\title{
Compatibility Studies of Valsartan with Different Pharmaceutical Excipients
}

\author{
IOANA CRISTINA TITA ${ }^{1}$, LAVINIA LUPA ${ }^{2}$, BOGDAN TITA ${ }^{3 *}$, ROXANA LIANA STAN ${ }^{4}$, LAURA VICAS ${ }^{1,5}$ \\ ${ }^{1}$ Carol Davila University of Medicine and Pharmacy, Faculty of Pharmacy, 6 Traian Vuia Str., 020956, Bucharest, Romania \\ 2Politehnica University Timisoara, Faculty of Industrial Chemistry and Environmental Engineering, 2 Victoriei Sq., 300006, \\ Timisoara, Romania \\ ${ }^{3}$ Vasile Goldis Western University of Arad, Faculty of Pharmacy, Department of Pharmaceutical Sciences, 86 L. Rebreanu Str., \\ 300041, Arad, Romania \\ ¿University of Medicine and Pharmacy luliu Hatieganu, Faculty of Pharmacy, 13 Emil Isaac Str., 400023, Cluj-Napoca, Romania \\ ${ }^{5}$ University of Oradea, Faculty of Medicine and Pharmacy, Speciality of Pharmacy, 29 Nicolae Jiga Str., 410028, Oradea, Romania
}

\begin{abstract}
Compatibility studies between active drugs and excipients are substantial in the pharmaceutical technology. Thermal analysis has been extensively used to obtain information about drug-excipient interactions and to perform pre-formulation studies of pharmaceutical dosage forms. The objective of the present study was to evaluate the compatibility of the valsartan (VALS) with pharmaceutical excipients of common use including diluents, binders, disintegrants, lubricants and solubilising agents. Thermogravimetry (TG), derivative thermogravimetry(DTG), butespecially differential scanning calorimetry (DSC) were used for a firstscreening to find small variations in peak temperature and/or their associated enthalpy for six drug/excipient mixtures (starch, cross caramelose sodique, microcrystalline cellulose 102, povidone K30, lactose monohydrate and magnesium stearate), which indicate some degree of interaction. Additional methods using Fourier transformed infrared spectroscopy (FT-IR) and X-ray powder diffraction (XRPD) confirmed the incompatibility of VALS with starch, povidone K30, lactose monohydrate and magnesium stearate. Those excipients should be avoided in the development of solid dosage forms.
\end{abstract}

Keywords: drug-excipient compatibility, valsartan, simultaneous TG/DTG/DSC

Cardiovascular disease is one of the most common chronic diseases in clinic; it causes high morbidity and mortality worldwide. When hearts suffer stress, the cardiac remodelling characterized by typical pathological cardiac hypertrophy occurs, resulting in heart failure [1].

Valsartan (VALS) (fig. 1), N-(1-oxopentyl)-N-[[2'(1Htetrazol-5-yl) [1,1'-bi-phenyl]-4-yl]methyl]-L-valine, is a selective angiotensin II type 1 receptor blocker indicated for the treatment of hypertension [2].<smiles>CCCCC(=O)N(Cc1ccc(-c2ccccc2-c2nn[nH]n2)cc1)[C@@H](C(=O)O)C(C)C</smiles>

Fig. 1. Chemical structure of Valsartan

Valsartan is a kind of anti-hypertensive drug and licensed for the treatment of patients with symptomatic heart failure, and itplays an important role in the process of heart failure injury [3].

The study of drug-excipient compatibility is an important stage in the development of a solid dosage form as their incompatibility can alter the stability and/or the biovailability of drugs, thereby, affecting its safety and/or efficacy. Two types of chemical incompatibilities have been described between excipients and drugs: those corresponding to intrinsic chemical drug degradation such hydrolysis or oxidation but without significant direct covalent chemical reactions, and those corresponding to covalent reaction between the drug and the excipient $[4,5]$.

Thermal analysis is a very useful technique for evaluating a range of different samples of the same material, to assess the influence of excipients on the physic-chemical properties of pharmaceutical materials and pharmaceutical dosage forms [6-9].

Throughout the different thermal methods reported on drug-excipient compatibility studies, DSC has been shown to be a rapid, sensitive and simple technique used in routine experiments. Small variations in peak temperature or associated enthalpy are interpreted as an indication of interaction and possible incompatibility [10-12].

Despite the advantages of DSC there are certain limitations. The extrapolation of findings obtained at high temperatures, are not always in agreement with the drug real situation in the formulation. Therefore, the DSC results must be interpreted carefully and some complementary techniques, such as Fourier transformed infrared spectroscopy (FT-IR) and X-ray powder diffraction (XRPD) can be useful in avoiding misleading conclusions [13-17].

In our previous papers we provided the importance of the thermal analysis in estimation on the thermal behaviour of different pharmaceuticals, respectively their possible interaction with excipients [18-21].

In this work, the characterization and the compatibility of valsartan (VALS) with six different pharmaceutical excipients of common use in the development of solid dosage forms was evaluated. For this purpose, simultaneous TG/DTG and especially DSC measurements were carried out on each of the components, both in the pure form and the corresponding 1:1 (w/w) physical mixtures. FT-IR spectroscopy and X-ray pow der diffraction (XRPD) were used as complementary techniques to adequately implement and assist in interpretation of the DSC results. 


\section{Experimental part}

Materials and samples

The valsartan (VALS), active substance, was obtained from Polisano Pharma SRL, (lot: VT0020911) as pure compound, able to be used for medical purpose.

The excipients were as follows: corn starch hydrated (Roquette Freres, France, lot: E1209); crosscarmelose sodique (CCS), microcrystalline cellulose PH 102 (MC 102) from J. Rettenmaier \& Sohne GmbH, Germany (lot: 5610273320); polyvinylpyrrolidone K30 (PVP K30 or PVP) from BASF Aktiengesellschaft, Germany (lot: 95658675LO); lactose monohydrate (a-lactose) from Friesland Foods Domo, Holland (lot: 620831); colloidal silicon dioxide $\left(\mathrm{SiO}_{2} \mathrm{C}\right)$ from Degussa $A G$, Germany (lot:3157040314) and magnesium stearate (MS) from Undesa, Spain (lot: 484931).

Physical mixtures of VALS with each selected excipient were prepared in the $1: 1(w: w)$ ratio by simple mixture of the components in an agate mortar with pestle for approximately $5 \mathrm{~min}$. The $1: 1(\mathrm{w} / \mathrm{w})$ ration was chosen in order to maximise the probability of observing any interaction.

\section{Methods}

Thermal analysis

The TG/DTG/DSC curves were recorded using a Netzsch-STA 449 TG/DTA instrument in the temperature range of $20-1000{ }^{\circ} \mathrm{C}$, under a dynamic atmosphere of nitrogen $\left(20 \mathrm{~mL} \times \mathrm{min}^{11}\right)$ and at a heating rate $(\beta)$ of 10 ${ }^{\circ} \mathrm{C} \times \mathrm{min}^{-1}$, using platinum crucibles and weighed samples of approximately $20 \mathrm{mg}$ of samples.

Fourier transformed infrared spectroscopy (FT-IR) and Xray diffraction

FT-IR spectra of drug, excipients and grinding mixtures were recorded on a Shimadzu Prestige 21 apparatus using $\mathrm{KBr}$ stressed discs in the range of $4000-400 \mathrm{~cm}^{-1}$.

$X$-ray diffraction patterns (XRPD), for the same category of substances, were obtained with a Rigaku Ultima IV diffractometer using CuK radiation.

\section{Results and discussions}

Thermal behaviour of VALS

The thermoanalytical curves of VALS are presented in figure 2.
In the temperature range $25-96{ }^{\circ} \mathrm{C}$, VALS eliminates the absorbed water $\left(\Delta \mathrm{m}=1.10 \%\right.$ and $\left.\mathrm{T}_{\text {peak } \mathrm{TTf}}=68.2^{\circ} \mathrm{C}\right)$. The nature of the process is endothermic and ${ }_{\text {peak DSC }}=68.2^{\circ} \mathrm{C}$.

Continuing the TG/DTG curves indicates a thermal stability of the VALS, while the DSC curve shows an endothermic peak $\left(\mathrm{T}_{\text {peak DSC }}=113.9^{\circ} \mathrm{C}\right)$, which corresponds to the melting of valsartan.

Thermal decomposition of VALS results in three distinct steps on the TG/DTG curves.

The first decomposition step takes place in the temperature range $174-275^{\circ} \mathrm{C}$, with $\mathrm{T}_{\text {peak } \mathrm{DTG}}=215.5^{\circ} \mathrm{C}$ and $\Delta \mathrm{m}=12.74 \%$. The DSC curve appears a bit broader, exothermic in nature, with $\mathrm{T}=235.5^{\circ} \mathrm{C}$.

After some thermal stability, the decomposition continued in the range $309-544^{\circ} \mathrm{C}$, with $\mathrm{T}_{\text {peak DTG }}=403.3^{\circ} \mathrm{C}$ and $\Delta m=68.88 \%$. On the DSC curve appears a small endothermic pic, relatively small, with $T_{\text {, }}{ }=408.1{ }^{\circ} \mathrm{C}$.

Thermal decomposition continues in the the third stage ( 544 $-871{ }^{\circ} \mathrm{C}$ ), with $\mathrm{T}_{\text {peak DTG }}=744.4^{\circ} \mathrm{C}$ and $\Delta \mathrm{m}=17.28 \%$. This latter process is accompanied by a large endothermic DSC curve with $\mathrm{T}_{\text {peak } \mathrm{DSC}}=703.0^{\circ} \mathrm{C}$.

\section{Compatibility study with excipients}

Thermal analysis in general and DSC in particular have been proposed to be rapid methods for evaluating physicochemical interactions between components of a formulation by comparing curves obtained for $1: 1(\mathrm{w}: \mathrm{w})$ physical mixtures and thus selecting suitable excipients with compatibility corresponding to.

Figures 3, 4 and 5 show the TG, DTG and DSC curves of the substances used in the compatibility study. Each curve shows a specific behaviour, depending on the characteristics of each excipient.

On the TG/DTG curves of starch there is a first mass loss $(\Delta \mathrm{m}=11.90 \%)$ in the temperature range $35-137^{\circ} \mathrm{C}$, with $\mathrm{T}_{\text {peak DTG }}=70.4^{\circ} \mathrm{C}$. Mass loss corresponds to the removal of water from the hydrated starch. This process is endothermic, highlighted on the DSC curve, with $\mathrm{T}_{\text {peak } \mathrm{DSC}}=$ $81.5^{\circ} \mathrm{C}$.

The thermal decomposition of starch is a relatively complex process, which takes place in two stages, partially distinct. The first stage, the main one, with $\Delta m=69.20 \%$, takes place in the range $255-397{ }^{\circ} \mathrm{C}$, and the DTG curve appears a bit sharp, with $\mathrm{T}_{\text {peak } \mathrm{DTG}}=314.8^{\circ} \mathrm{C}$. At the same time, two peaks of endothermic nature appear on the DSC curve:

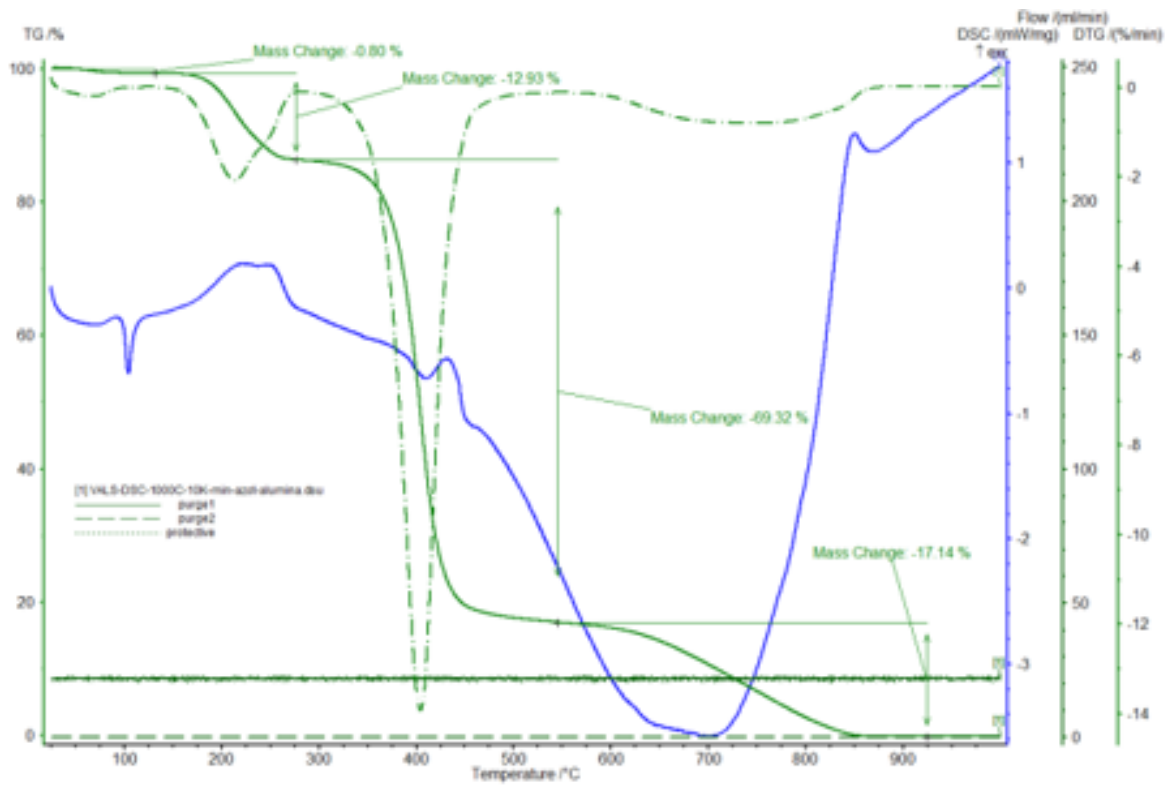

Fig. 2. TG/DTG/DSC curves of pure VALS 

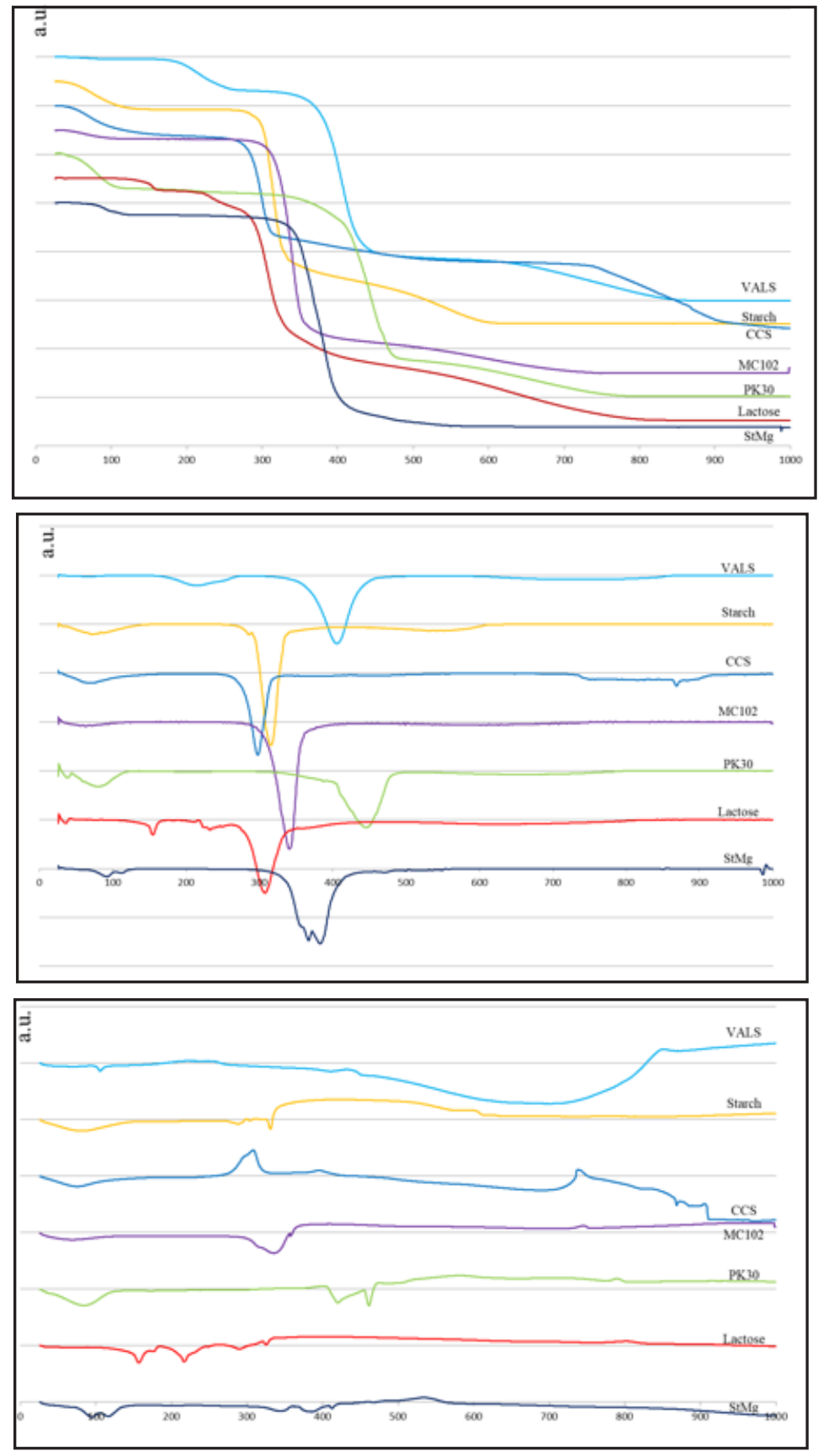

- a slightly smaller first, with $\mathrm{T}_{\text {peak } \mathrm{ns}}=286.7^{\circ} \mathrm{C}$, accompanied by a shoulder on the right side at $306.8^{\circ} \mathrm{C}$; - the second bigger, sharp, appears at a temperature of $329.6^{\circ} \mathrm{C}$.

In the second decomposition step, corresponding to the range $397-625^{\circ} \mathrm{C}$, the mass loss is $18.9 \%$, and on the DTG curve appears a bit wide, with $\mathrm{T}_{\text {peak } D T G}=544.4^{\circ} \mathrm{C}$. On the DSC curve two small peaks of endothermic nature at temperatures of $580.0^{\circ} \mathrm{C}$, respectively $610.4^{\circ} \mathrm{C}$.

The thermal behaviour of croscarmellose sodium is interesting from the point of view of the nature of the thermal effects of thermal decomposition but also of the complex decomposition process itself.

In the temperature range $25-187^{\circ} \mathrm{C}$, with $\mathrm{T}_{\text {, }}=$ $68.2^{\circ} \mathrm{C}$, dehydration takes place. Mass loss is $12.70 \%$, and the DSC curve shows an endothermic peak, with $\mathrm{T}_{\text {peak DSC }}$ $=75.6^{\circ} \mathrm{C}$.

Thermal decomposition begins immediately after the $187^{\circ} \mathrm{C}$ temperature, in a first step $\left(187-598^{\circ} \mathrm{C}\right)$, with a bit sharp, on the DTG curve and $\mathrm{T}{ }^{\circ}=299.5^{\circ} \mathrm{C}$. The mass loss is $51.80 \%$, and the DSC curve shows two peaks of exothermic nature:
Fig. 3. TG curves of all substances used in compatibility study

Fig. 4. DTG curves of all substances used in compatibility study

Fig. 5. DSC curves of all substances used in compatibility study 
In the first stage, as a percentage of lost weight $(\Delta \mathrm{m}=$ $89.60 \%)$, two sharp, high peaks with $\mathrm{T}_{\text {peak } \text { DTG }}=340.7^{\circ} \mathrm{C}$, respectively $T_{\text {eak }}=337.0^{\circ} \mathrm{C}$, appear on the DTG and DSC curves, the latter being of nature endothermic.

The second stage has a mass loss of only $6.48 \%$, and the DTG curve does not actually show a peak, with the mass variation taking place around the temperature of $625.0^{\circ} \mathrm{C}$. The DSC curve shows a peak of exothermic nature with $\mathrm{T}_{\text {peak } \mathrm{DSC}}=742.9^{\circ} \mathrm{C}$

The first process evidenced by the thermal curves of povidone K30 corresponds to the dehydration process. This takes place in the temperature range $37-133^{\circ} \mathrm{C}$, with $\mathrm{T}$ $=T_{\text {peaksc }}=80.0^{\circ} \mathrm{C}$, and the nature of the phenomenon

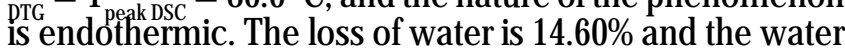
is easily removed, but the total mass of lost water depends on the moisture content of the atmosphere (eg dry or wet $\mathrm{N}_{2}$ ). Also, the shape of the DSC peak (its width) depends on the relative humidity of the atmosphere above the sample. Apparently, dehydration is complete at $137^{\circ} \mathrm{C}$ in $\mathrm{N}_{2}$. How ever, a secondary water loss step $(\Delta \mathrm{m}=2.20 \%)$ starts after $137^{\circ} \mathrm{C}$ and is complete around $319^{\circ} \mathrm{C}$. There are no significant peaks on the DTG and DSC curves. Thermal analysis SEM and XRPD all show that the compound is in a vitreous phase with a glass transition near $200^{\circ} \mathrm{C}$.

The thermal decomposition takes place in the temperature ranges $319-504{ }^{\circ} \mathrm{C}$, respectively $504-813^{\circ} \mathrm{C}$.

The firststep $\left(319-504^{\circ} \mathrm{C}\right)$ implies a mass loss of $69.10 \%$, and a sharp high peak with a $\mathrm{T}{ }_{\text {ine }}=442.2^{\circ} \mathrm{C}$ is present on the DTG curve, while on the DSC curve two high endothermic peaks and sharpened at $414.8^{\circ} \mathrm{C}$, respectively $457.7^{\circ} \mathrm{C}$.

The second step $\left(504-813^{\circ} \mathrm{C}\right)$, with a mass look of $16.10 \%$, shows a wide peak on the DTG curve, with the socalled maximum at $657.7^{\circ} \mathrm{C}$, and on the DSC curve two peaks: the first of exothermic nature at $575.0^{\circ} \mathrm{C}$ and the second endothermic at $774.0^{\circ} \mathrm{C}$.

The amorphous ( $100 \%$ ) form of lactose can be identified by thermal analysis, more precisely based on the DSC technique, whose curve exhibits an exothermic peak at $167^{\circ} \mathrm{C}$, which represents the transformation of the amorphous form into crystalline form. It is hatched by two endothermic peaks, one at $210^{\circ} \mathrm{C}$ and the other at $216^{\circ} \mathrm{C}$. These peaks correspond to the melting of $\alpha$-lactose (lactose monohydrate), respectively $\beta$-lactose (anhydrous lactose), which means that the two forms are present in differentproportions.

Also, 100\% crystalline lactose, according to the XRPD method, contains forms $\alpha$ and $\beta$.

According to the thermogram, the water content $(4.88 \%)$ of lactose monohydrate is maintained at about $165^{\circ} \mathrm{C}$. Practically, water is removed between 127 and $167^{\circ} \mathrm{C}$, with $\mathrm{T}=150.3^{\circ} \mathrm{C}$. Water loss is accompanied by a strong endodothermic effect on DSC curve ( $\mathrm{T}_{\text {peak DSC }}=$ $151.8^{\circ} \mathrm{C}$ ).

There is then a slight loss of mass $(\Delta \mathrm{m}=1.00 \%)$, the compound being stable to about $215^{\circ} \mathrm{C}$, after which it decomposes. Prior to decomposition, melting of lactose (in fact $\alpha$-lactose) occurs, the process being characterized by a strong endothermic peak $\left(T=214^{\circ} \mathrm{C}\right)$. Immediately after melting, in the range of $215-259^{\circ} \mathrm{C}$, with $\mathrm{T}=232.6^{\circ} \mathrm{C}$ and a loss of weight of $6.48 \%$, decomposition of $\beta$-lactose (present along with $\alpha$-lactose) occurs. This process is accompanied on the DSC curve by a high endothermal sharp peak $\left(T_{\text {peak DsC }}=215.5^{\circ} \mathrm{C}\right)$.

After these processes the actual decomposition takes place, the so-called main process, a complex one, which takes place in two stages.
The first step takes place between 259 and $513^{\circ} \mathrm{C}$, with a high peak on the DTG curve, having a $T$. $=304.5^{\circ} \mathrm{C}$. On the DSC curve there are two sufficiently large, endothermic, respectively exothermic peaks with the appropriate temperatures: $\mathrm{T}_{\text {peak }}$ Dsc end $=289.5^{\circ} \mathrm{C}$ and $\mathrm{T}_{\text {peak }}$ DSC ${ }_{\text {exo }}=319.2^{\circ} \mathrm{C}$. The mass pess is $68.00 \%$.

The decomposition process continues with the second stage, in the temperature range $513-835^{\circ} \mathrm{C}$, characterized by a broad peak on the DTG curve, with $\mathrm{T}_{\text {peak } \mathrm{DTG}}=625.0^{\circ} \mathrm{C}$.

Like the DTG curve, the DSC curve indicates the complexity of the process and the relatively wide temperature range in which it occurs by the emergence of two small peaks of exothermic nature at $698.0^{\circ} \mathrm{C}$, respectively $723.0^{\circ} \mathrm{C}$, as well as by the occurrence of a significant exothermic peak, with $\mathrm{T}_{\text {peak } \mathrm{DSC}}=800.0^{\circ} \mathrm{C}$. The loss of mass suffered is $20.50 \%$.

In the case of colloidal $\mathrm{SiO}_{2}$, in the temperature range $33-144^{\circ} \mathrm{C}$, a small mass loss ( $\left.{ }^{\prime} \mathrm{m}=1.08 \%\right)$ occurs on the TG curve due to the probable and possible humidity adsorbed, especially due to the area of the specific surface area. The DSC curve shows an endothermic peak, with $\mathrm{T}_{\text {peak } \text { DSC }}=51.2^{\circ} \mathrm{C}$. Next, up to $400^{\circ} \mathrm{C}$, no mass variation occ urs, but a small endothermic peak with $\mathrm{T}$. ${ }^{\circ} \mathrm{C}$ appears on the DSC curve. The presence of this peak may be due to a phenomenon of physical nature, insignificant, however.

In the temperature range $400-1000{ }^{\circ} \mathrm{C}$ there is a slight decrease in mass $(\Delta m=0.92 \%)$, and on the DSC curve there is an endothermic peak with $T_{\text {peak DSC }}=841.4^{\circ} \mathrm{C}$. The magnitude of the peak on the DSC curve, correlated with mass variation, may also indicate the presence of a physical phenomenon.

With the start of heating of magnesium stearate (StMg), in the temperature range $51-130^{\circ} \mathrm{C}$, the TG curve shows a mass loss $(\Delta m=5.00 \%)$, which corresponds to the dehydration process. Water loss is a process of endothermic nature, highlighted by the appearance of a high peak characteristic on the DSC curve, and $\mathrm{T}_{\text {peak DSC }}=\mathrm{T}_{\text {peak DTG }}=$ $94.1^{\circ} \mathrm{C}$. With dehydration, the melting proces DS alSo takes place, which usually overlaps with dehydration or even moves to lower temperatures. In this case, the corresponding well defined peak $\left(\mathrm{T}_{\text {peak DSC }}=114.8^{\circ} \mathrm{C}\right)$ due to the presence of the dehydration peak appears as a larger shoulder to the right of the latter.

In the range of $130-285^{\circ} \mathrm{C}$, two extremely small endothermic peaks at $198.1^{\circ} \mathrm{C}$ and $274.6^{\circ} \mathrm{C}$ are present on the DSC curve due to the impurities existing as magnesium palmitate and others with higher melting temperatures. Within this range there is also a very small variation (decrease) in mass $(\Delta \mathrm{m}=1.00 \%)$.

The thermal decomposition of magnesium stearate takes place in a single step, corresponding to the range $285-607{ }^{\circ} \mathrm{C}$, but in the form of a very complex process, evidenced by the DSC curve, by the presence of a large number of different peaks as a thermal effect.

The DTG curve shows a high peak $\left(\mathrm{T}_{\text {peak DTG }}=382.9^{\circ} \mathrm{C}\right)$ and a total mass loss of $86.00 \%$. As mentioned, on the DSC curve there are a series of endothermic peak, significant in size at the following temperature: $344.4^{\circ} \mathrm{C}, 388.1{ }^{\circ} \mathrm{C}$, respectively $414.8^{\circ} \mathrm{C}$.

After the largest part of $\mathrm{StMg}(\Delta \mathrm{m}=80.00 \%)$ was decomposed, a series of processes of exothermic nature took place due to the appearance of a large exothermic peak $\left(\mathrm{T}_{\text {peak }} \mathrm{DSC}=537.0^{\circ} \mathrm{C}\right)$ preceded by three small exothermic peaks so-called shoulders), at temperatures: $429.6^{\circ} \mathrm{C} ; 459.2^{\circ} \mathrm{C}$ and $482.2^{\circ} \mathrm{C}$. Mass loss in this lastinterval $\left(415-607{ }^{\circ} \mathrm{C}\right.$ ) is $6.00 \%$. The residual mass is $8.00 \%$. 
TG/DTG and DSC curves of the pure VALS and the 1:1 drug:excipient physical mixture are shown in figures 6, 7 and 8.

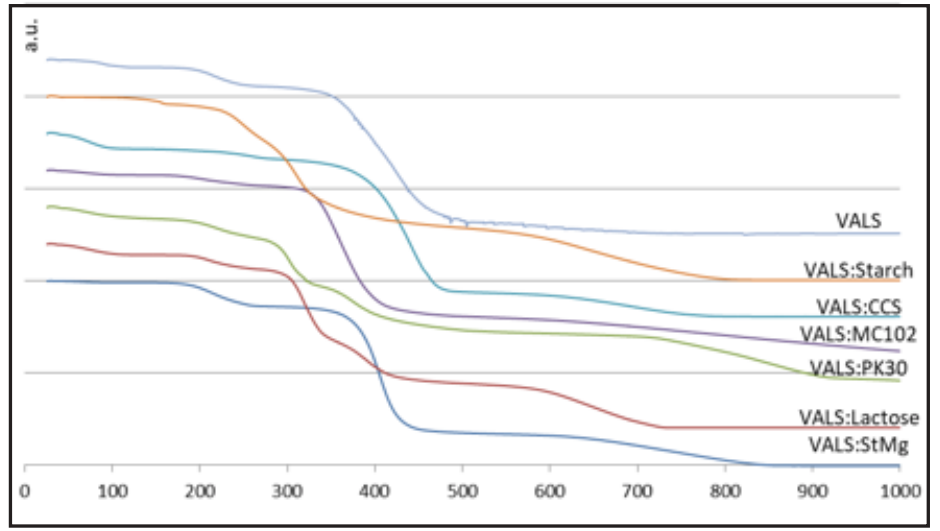

Fig. 6. TG curves of pure VALS and the 1:1 drug:excipient physical mixture

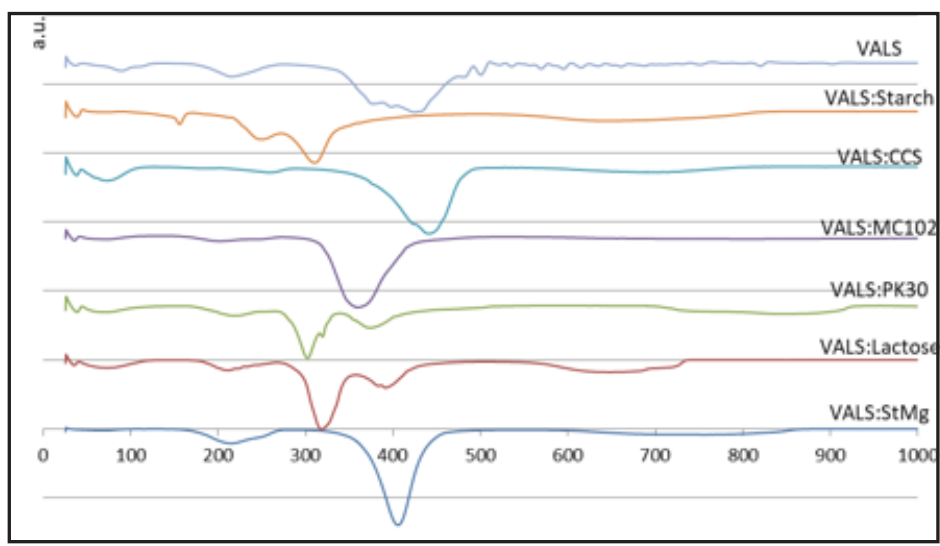

Fig. 7. DTG curves of pure VALS and the 1:1 drug:excipient physical mixture

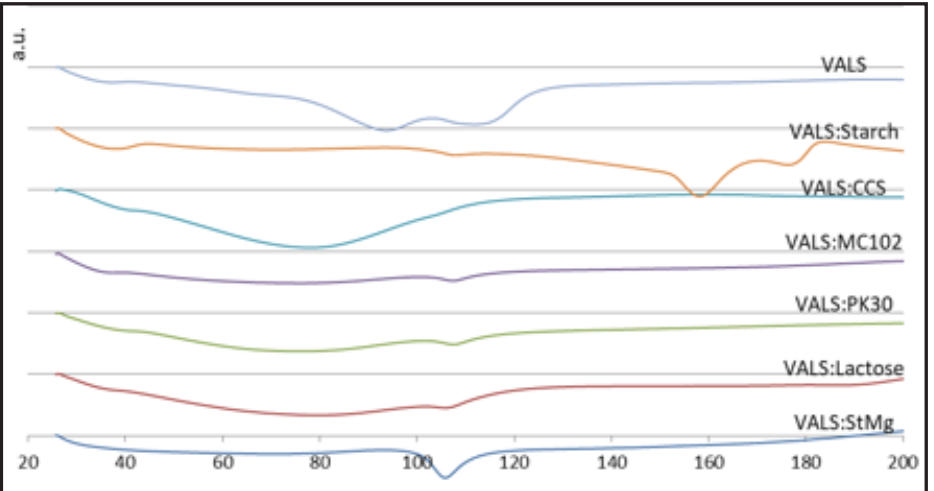

In the 1:1 physical mixtures when there is no any interaction between drug and excipient, the $T_{\text {pak }}$ value of melting event (DSC curve) and the first stage of the decomposition ( $T_{\text {onset }}$ and $T_{\text {peak }}$ of TG/DTG curves) should remain practically unchenanged, similarly when the drug is alone. In this case the thermal profiles of the mixture can be considered as a superposition of the curves of VALS and excipients. In the DSC curve the $T_{\text {peak- }}$ value of melting of the drug is alone, or in its mixtures when there is no interaction between drug and excipient.

According to the thermal curves (figs. 6-8), in particular the DSC curves that provide the most complete information, differences were found to be higher or lower (in the case of mixtures with starch, povidone K30, lactose monohydrate and magnesium stearate) melting temperature values, melting enthalpy values and thermal decomposition ranges. In principle, all other excipients exhibit some small but melting differences with respect to the melting temperature, respectively the value of the melting enthalpy (table 1). These differences may be due to small interactions that have not been confirmed by FTIR spectroscopy and X-ray diffraction (XRPD).
In the case of the VALS starch mixture, the DSC curve of the VALS:starch 1:1 mixture of compared to the VALS DSC curve shows a very small, almost insignificant peak at about the same temperature as that corresponding to the melting temperature of the VALS. Practically, the so-called melting peak appears as a very small shoulder to the right of the dehydration peak, shifted to a lower temperature.

The very low-to-disappearance dimensions of the VALS melting peak, which is confirmed by the extreme low value of $\Delta \mathrm{H}_{\text {fusion }}$ (table 1), indicate a strong chemical interaction of VALS with starch. The so-called peak present in the DSC curve is probably due to VALS residues after mixing.

The TG/DTG curves of this binary mixture showed that the beginning of the decomposition step of VALS was shifted towards a lower temperature. The values observed to this temperatures are $\mathrm{T}_{\text {onset }}=218 ; 354$ and $496{ }^{\circ} \mathrm{C}$ lower than the values obtained to the corresponding event in TG/ DTG curves of VALS alone (table 1). Also, $T_{\text {peak DTG }}$ are with approximately $100{ }^{\circ} \mathrm{C}$ lower (table 1). These modifications of the temperature's values showed a reduction of thermal stability for VALS in the presence of starch, due to the mentioned interaction. 
The DSC curve of the physical mix of VALS with PK30 shows a broad and strong peak corresponding to dehydration between 25 and $113^{\circ} \mathrm{C}$ with T $\mathrm{T}_{\text {peak DSC }}=75.0^{\circ} \mathrm{C}$. The main characteristic of the DSC curve is the disappearance of the characteristic melting peak of VALS.

The disappearance of the characteristic peak for VALS melting is an indication of a chemical interaction between these substances due to heating. The rationale for this behaviour can be due to the lower temperature change of the VALS peak, which could fuse with the water loss peak of PK30 $\left(25-113{ }^{\circ} \mathrm{C}\right)$. Another possibility is the one that includes all the water removed from the PK30, resulting in the dissolution of the VALS, due to which the VALS peak disappears.

Such behaviour has been described in the literature for PK30 mixtures with other drug substances such as naproxen, ketoprofen, ibuprofen, sodium diclofenac, acetylsalicylic acid, indicating the occurrence of a solidsolid interaction with heating. It is believed that this mode of interaction takes place by the so-called dissolution of VALS in the presence of humidity and heating.

The TG/DTG curves of the binary mixture showed that the start of the VALS decomposition step $\left(T_{\text {nnse }}=T_{\text {i }}\right.$ ) was shifted to a lower temperature. The observed value for this temperature is lower than the corresponding VALS decomposition temperature (table 1 ). In the same way, DTG peak temperatures are also modified. Currently, the movement is due to a structural change and indicates interaction, i.e. incompatibility between VALS and PK30.

Also, these changes in temperature values show a reduction in thermal stability for VALS in the presence of PK30, due to the interaction mentioned.

The DSC curve of the physical mixture of VALS with lactose monohydrate presents a broad and weak peak which corresponds to the elimination of the adsorbed water, between $41-94{ }^{\circ} \mathrm{C}$ with $T_{\text {peak DSC }}=66.7{ }^{\circ} \mathrm{C}$. This event is followed by a broad and strong peak which correspond to the elimination of the crystallisation water between $94-167^{\circ} \mathrm{C}\left(\mathrm{T}_{\text {peak } \mathrm{RSC}}=154.0^{\circ} \mathrm{C}\right)$. The main finding of the DSC curve is practically the disappearance of the characteristic VALS fusion peak.

Practically, the DSC curve has a very small, almost insignificant peak, at about the same temperature as the corresponding melting temperature of the VALS. This socalled melting peak appears as a very small shoulder to the left of the crystallization water removal peak. The very low-to-disappearance dimensions of the VALS melting peak, which is confirmed by the very low value of $\Delta \mathrm{H}_{\text {f }}$ (table 1), indicate a strong chemical interaction of VÁLs with $\alpha$-lactose due to heating.

Regarding the TG/DTG curves it is found that the beginning of the decomposition steps of the VALS is shifted to lower temperatures. The values observed at these temperatures are $\mathrm{T}=167 ; 268$ and $481^{\circ} \mathrm{C}$ lower than those obtained with VÁLS alone: 309 and $544^{\circ} \mathrm{C}$ (table 1). Also, $\mathrm{T}_{\text {peak DTG }}$ is about $90-100{ }^{\circ} \mathrm{C}$ lower (table 1 ). As in previous cases, moving these temperatures to lower values reduces the thermal stability of VALS.

By comparing the DSC curves of VALS pure and StMg to those of a 1:1 physical mixture, the differences are quite visible and can be attributed to an incompatibility (interaction) between the two components.

The endothermic peak corresponding to the VALS melt disappears and a new one appears overlapping with the so-called double peak corresponding to the dehydration and StMg melting (92.6 and $107.4{ }^{\circ} \mathrm{C}$ ), which is slightly shifted to lower temperatures than the StMg peak. Under these circumstances, the $\Delta \mathrm{H}_{\text {fusion }}$ value will be higher.

A further explanation for this interaction is that StMg used is a mixture of magnesium salts of different fatty acids (mostly stearic acid and palmitic acid, respectively, other low fat acids), whose melting temperature is lower.

In literature, such interactions of StMg with drug substances such as atenolol, captopril, ibuprofen, ketoprofen, sodium diclofenac, acetylsalicylic acid, etc. are reported in literature.

Regarding the influence of StMg on the TG/DTG curves, it is manifested in the same way as in the above cases.

In accordance with the values (especially $\mathrm{T}_{i}$ and $\Delta \mathrm{H}_{\text {fusion }}$ ) form table 1 , on establish that, generally, the melting peas of VALS was preserved and the enthalpy's values are reduced to half, less for the four binary mixtures mentioned. The slight lowering and/or broadening of the melting temperature, respectively beginning and maximum temperature of decomposition may be attributed to the mixing process, which lower the purity of each component in the mixture.

Appreciably decreasing or the absence of the melting temperature, respectively values of $\Delta \mathrm{H}_{\text {fusion, }}$, suggests a process which takes place with low intensity or even disappears (the case of binary mixture VALS-PK30).

A higher value of $\Delta \mathrm{H}_{\text {fusion }}$ shows an overlapping of two processes (the case of binary mixture VALS-StMg, with melting and dehydration).

Table 1

THERMOANALYTICAL DATA FOR VALS AND EXCIPIENTS

\begin{tabular}{|c|c|c|c|c|c|c|}
\hline \multirow[b]{2}{*}{ Samples } & \multicolumn{2}{|c|}{ DSC } & \multirow{2}{*}{$\frac{\Delta \mathrm{H}_{\text {fusion }}}{\left(\mathrm{Jg}^{-1}\right)}$} & \multicolumn{2}{|c|}{ DTG } & \multirow[b]{2}{*}{$\Delta \mathrm{m}(\%)$} \\
\hline & $\begin{array}{l}\mathrm{T}_{\text {ousat }} / \\
\text { (fasion) }\end{array}$ & $\begin{array}{c}\mathrm{T}_{\text {pouk }} / \\
\text { (faxion) } \\
{ }^{\circ} \mathrm{C}\end{array}$ & & $\mathrm{T}_{\text {oussot }} /{ }^{\circ} \mathrm{C}$ & $\mathrm{T}_{\text {pask }} /{ }^{\circ} \mathrm{C}$ & \\
\hline \multicolumn{7}{|l|}{ Drug } \\
\hline VALS & 104.3 & 113.9 & 386.2 & $\begin{array}{c}25 ; 174 \\
309 ; 544\end{array}$ & $\begin{array}{c}68 ; 216 \\
403 ; 744\end{array}$ & $\begin{array}{c}1.1 ; 12.7 \\
68.9 ; 17.3\end{array}$ \\
\hline \multicolumn{7}{|l|}{ Drug/excipient } \\
\hline Starch & 108.0 & 114.7 & 32.4 & $\begin{array}{c}25 ; 178 \\
268 ; 354 ; 496\end{array}$ & $\begin{array}{c}67 ; 206 \\
315 ; 390 ; 644\end{array}$ & $\begin{array}{c}6.3 ; 7.2 \\
40.3 ; 21.3 ; 24.9\end{array}$ \\
\hline $\mathrm{SiO}_{2}$ & 108.0 & 115.4 & 117.3 & $\begin{array}{c}25 ; 158 \\
246 ; 338 ; 612\end{array}$ & $\begin{array}{c}70 ; 219 \\
303 ; 374 ; 855\end{array}$ & $\begin{array}{c}6.5 ; 9.0 \\
27.8 ; 25.7 ; 24.9\end{array}$ \\
\hline CM102 & 105.0 & 112.4 & 183.5 & $\begin{array}{c}25 ; 135 \\
274 ; 496\end{array}$ & $\begin{array}{c}67 ; 201 \\
359 ; 720\end{array}$ & $\begin{array}{c}2.5 ; 6.1 \\
70.9 ; 18.9\end{array}$ \\
\hline $\mathrm{PK} 30^{\circ}$ & * & 8 & * & $\begin{array}{c}25 ; 126 \\
288 ; 524\end{array}$ & $\begin{array}{c}71 ; 259 \\
437 ; 696\end{array}$ & $\begin{array}{c}8.1 ; 5.9 \\
73.0 ; 13.0\end{array}$ \\
\hline$\alpha$-lactose & 102.1 & 113.2 & 34.6 & $\begin{array}{c}25 ; 95 \\
167 ; 268 ; 481\end{array}$ & $\begin{array}{c}37 ; 147 \\
246 ; 306 ; 637\end{array}$ & $\begin{array}{c}0.9 ; 2.9 \\
20.0 ; 46.9 ; 29.2\end{array}$ \\
\hline STMg** & 108.0 & 115.4 & 363.7 & $\begin{array}{c}25 ; 170 \\
279 ; 520\end{array}$ & $\begin{array}{c}85 ; 214 \\
376 ; 424 ; 662\end{array}$ & $\begin{array}{l}4.3 ; 10.9 \\
73.0 ; 6.2\end{array}$ \\
\hline
\end{tabular}


The small variations in the enthalpy's values for the binary mixtures can be attributed to some heterogeneity in the small samples used for the DSC experiments (3-4 $\mathrm{mg}$ ).

The difference of enthalpy for the binary mixture VALS$\mathrm{SiO}_{2}$ can suggest a physical interaction which not determines an incompatibility.

\section{FT-IR spectroscopy}

The FT-IR spectroscopy was used as a supplementary technique in order to investigate the possible chemical interaction between drug and excipient and to confirm the results obtained by the thermal analysis. It is the most suitable technique of the non-destructive spectroscopic methods and has become an attractive method in the analysis of pharmaceutical solids, since the materials are not subject to thermal or mechanical energy during sample's preparation, therefore preventing solid-state transformations. The appearances of new absorption
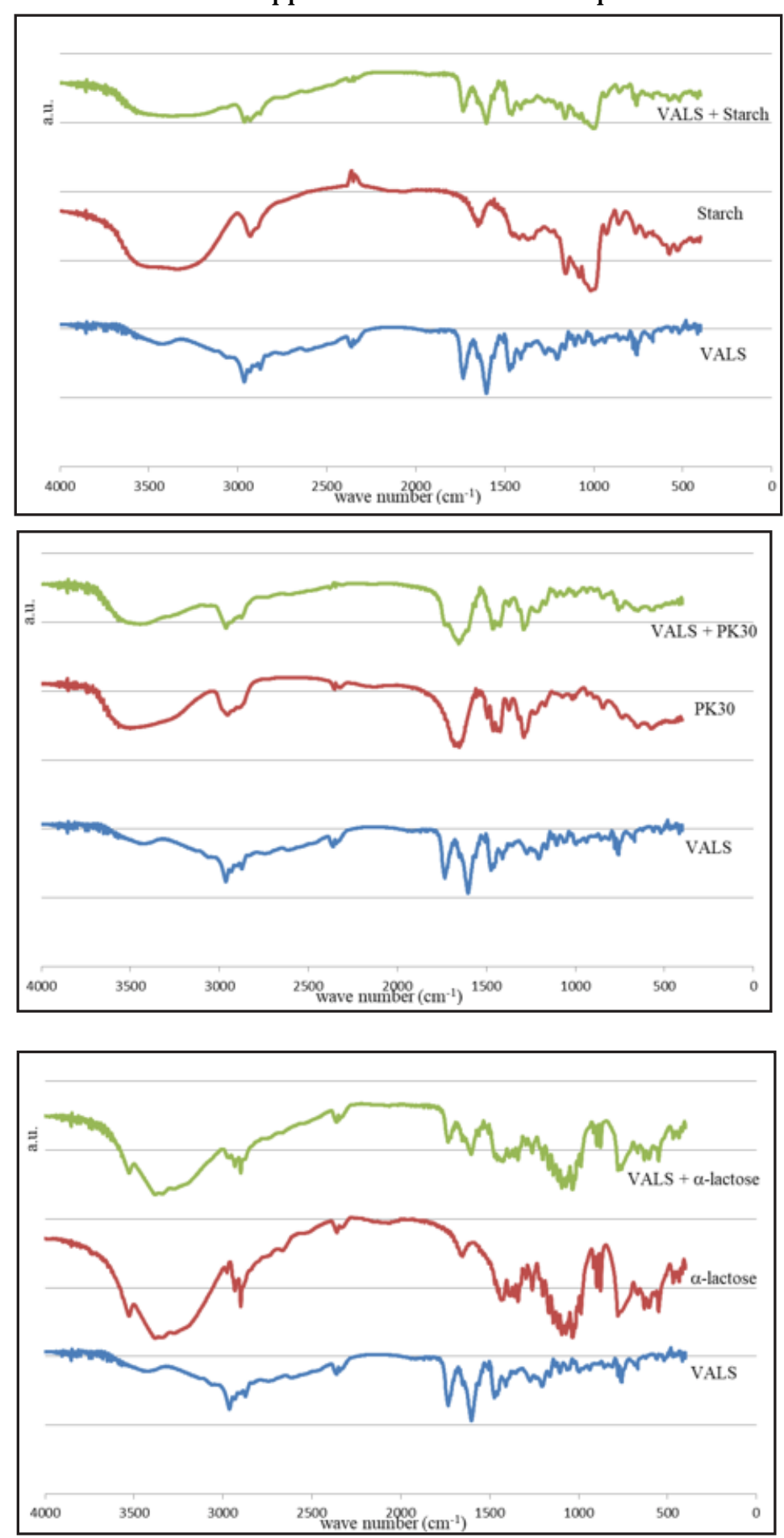

Fig. 11. IR spectra of VALS, $\alpha$-lactose and 1:1 blend as simple mixture of VALS and $\alpha$-lactose.
Fig. 10. IR spectra of VALS, PK30 and 1:1 blend as simple mixture of VALS and PK30.

The FT-IR spectra were drawn for VALS, excipients, spectively for the corresponding mixtures.

For the binary mixtures which present compatibility according the DSC results, the FT-IR spectra can be without absence shift orbroadening in the vibration bands FALS. So, itconfirms the absence of physical or chemical excipients.

Further, it will be presented only the spectra for the cases where the thermal analysis indicates a possible interaction, namely: VALS, starch, povidone K30, lactose monohydrate magnesium stearate, respectively the corresponding mixture of VALS with each excipient mentioned (fig. 9 -

Fig. 9. IR spectra of VALS, Starch and 1:1 blend as simple mixture of VALS and Starch. 


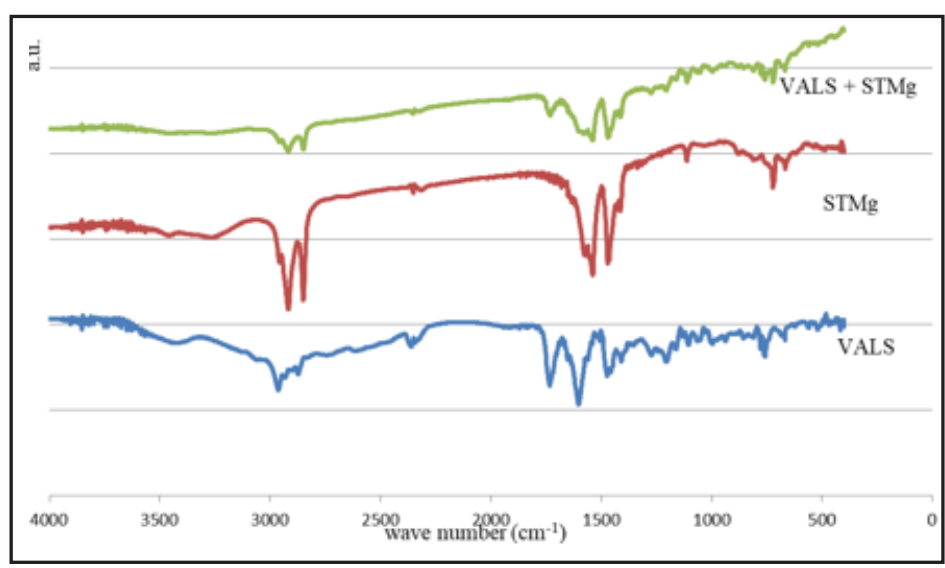

Fig. 12. IR spectra of VALS, StMg and 1:1 blend as simple mixture of VALS and StMg.

The VALS spectrum was in accordance with the literature, which in the region of $3600-3350 \mathrm{~cm}^{-1}$ describes a weak and large band (the maximum at $3426 \mathrm{~cm}^{-1}$ ) attributed to the $\mathrm{O}-\mathrm{H}$ stretching vibration (carboxyl group) as well as to the $\mathrm{N}-\mathrm{H}$ stretching vibration. In the region $3000-2600 \mathrm{~cm}^{-1}$, at 2965; 2874; 2745 and $2616 \mathrm{~cm}^{-1}$, are observed four bands intensity medium which correspond to asymmetric, respectively symmetric $\mathrm{C}-\mathrm{H}$ stretching vibration (from: $\mathrm{CH}_{3} ; \mathrm{CH}_{2}$ ). A band of medium intensity appears at $1732 \mathrm{~cm}^{-1}$ and is characteristic to the $\mathrm{C}=0$ stretching vibration. The most intense band appears at 1603 $\mathrm{cm}^{-1}$ and corresponds to the $\mathrm{C}=\mathrm{N}$ and $\mathrm{C}=\mathrm{C}$ stretching vibration.

The two bands from the region $1470-1410 \mathrm{~cm}^{-1}$ correspond to the $\mathrm{COO}^{-}$(asymmetric, respectively symmetric) vibrations, respectively $C-C$ ring stretching and $\mathrm{N}=\mathrm{N}$ vibrations. In the region $1280-1160 \mathrm{~cm}^{-1}$, appear three bands of medium intensity at 1274; 1206 and 1165 $\mathrm{cm}^{-1}$, that correspond to the $\mathrm{C}-\mathrm{H}\left(\delta_{2} \mathrm{CH}_{3} ; \mathrm{CH}_{2} ; \mathrm{CH}\right.$ and $\mathrm{\delta}_{\text {sym. }} \mathrm{CH}_{3} ; \mathrm{CH}_{2} ; \mathrm{CH}$ ) and $\mathrm{C}-\mathrm{N}$ vibrations. The four bands of weak intensity, at 1105; 1057; 997 and $939 \mathrm{~cm}^{-1}$ correspond to the $\mathrm{C}-\mathrm{O}\left(\mathrm{v}_{\mathrm{c}-\mathrm{C}-\mathrm{O}} ; \mathrm{v}_{\mathrm{C}-\mathrm{Cl}=0 \mathrm{O}-\mathrm{O}}\right)$ and $\mathrm{C}-\mathrm{C}$ vibrations, respectively in plane and out plane $\mathrm{C}-\mathrm{H}$ bending. The bands at 816 and $758 \mathrm{~cm}^{-1}$ correspond to the out-of-plane $\mathrm{C}-\mathrm{H}$ bending from phenyl ring. The weak bands in the region of $677 \mathrm{~cm}^{-1}$ corresponds to the out-of-plane $\mathrm{C}=\mathrm{C}$ bending from phenyl ring, to the out-of-plane $\mathrm{N}-\mathrm{H}$ bending and to the out-ofplane $\mathrm{O}-\mathrm{H}$ bending. In the region of $565-515 \mathrm{~cm}^{-1}$, the bands which appear correspond to the out-of-plane $\mathrm{C}-\mathrm{H}$ bending from benzene substituted.

The spectrum of the starch presents a medium and large band in the region $3600-3100 \mathrm{~cm}^{-1}$ (the maximum at 3363 $\mathrm{cm}^{-1}$ ) which corresponds to $\mathrm{OH}$ group from the hydration water as well as from the starch molecule. The band of medium intensity at $2932 \mathrm{~cm}^{-1}$ is attributed to the $\mathrm{C}-\mathrm{H}$ stretching vibration from the methylene group. In the region of $1645 \mathrm{~cm}^{-1}$ is present a weak band, which correspond to the $\mathrm{C}-\mathrm{O}$ (from ether) stretching vibration. The range of $1427-1360 \mathrm{~cm}^{-1}$ corresponds to the $0-\mathrm{H}$ bending vibrations (in plane). The bands from 1157 and $1080 \mathrm{~cm}^{-1}$ of medium intensity, respectively from $1016 \mathrm{~cm}^{-1}$ of medium-strong intensity, correspond to the $\mathrm{C}-\mathrm{O}$ ( $\mathrm{C}-\mathrm{C}-\mathrm{O})$ stretching vibration, respectively to the in-plane $\mathrm{C}-\mathrm{H}$ bending from ring. In the region of $930-710 \mathrm{~cm}^{-1}$ there are four bands of weak intensity which correspond to the out-of-plane $\mathrm{C}-\mathrm{H}$ bending from ring. The bands from 575 and $525 \mathrm{~cm}^{-1}$ of weak intensity correspond to the out-of-plane $\mathrm{C}-\mathrm{H}$ bending from ring substituted.

For the binary mixture, it shows the following differences:

- the significant increase $(\approx 50 \%)$ of the band attributed to the $\mathrm{OH}$ and $\mathrm{NH}$ groups $\left(3426 \mathrm{~cm}^{-1}\right)$ from the VALS spectrum, with the movement of the absorptions maximum at $3371 \mathrm{~cm}^{-1}$;
- it appears a doublet at 2963 and $2932 \mathrm{~cm}^{-1}$ instead of the bands from 2965; 2874; 2745 and $2616 \mathrm{~cm}^{-1}$ (VALS) and $2932 \mathrm{~cm}^{-1}$ (starch);

- the disappearance of the band at $1645 \mathrm{~cm}^{-1}$ from starch spectrum;

- the disappearance of the bands from $1273 \mathrm{~cm}^{-1}$ (VALS) and $1016 \mathrm{~cm}^{-1}$ (starch);

- the movement of the bands from 1105 and $1059 \mathrm{~cm}^{-1}$ at 1082 (VALS), respectively $1049 \mathrm{~cm}^{-1}$ and the increase of the intensity with $\approx 60 \%$, respectively $\approx 65 \%$;

- the significant increase ( $\approx 80 \%)$ of the intensity for the band from $997 \mathrm{~cm}^{-1}$ (VALS);

- the disappearance of the band at $677 \mathrm{~cm}^{-1}$ from the VALS spectrum.

The FT-IR spectrum for the physical mixture between VALS and starch suggests some chemical interactions

In respect of the povidone $\mathrm{K} 30$, it presents the following bands, at:

- $3507 \mathrm{~cm}^{-1}$ - a large band ( $3600-3100 \mathrm{~cm}^{-1}$ ) at medium intensity, attributed to the $\mathrm{OH}$ group from the crystallisation water;

- $2955 \mathrm{~cm}^{-1}$ a band of medium intensity, which corresponds to the $\mathrm{C}=0$ bending;

- $1661 \mathrm{~cm}^{-1}$ - a band of strong intensity as a triplet that corresponds to the carbonyl amidic group;

- 1495; 1464; $1423 \mathrm{~cm}^{-1}$ - these correspond to asymmetrical and symmetrical vibrations of $\mathrm{C}-\mathrm{H}$ from $\mathrm{CH}_{2}$ and $\mathrm{CH}$ groups;

- 1290; 1229; $1171 \mathrm{~cm}^{-1}$ - that correspond to the in plane and out-of-plane $\mathrm{C}-\mathrm{H}$ bending;

- 845; 737; $650 \mathrm{~cm}^{-1}$-these correspond to out-of-plane $\mathrm{C}-\mathrm{H}$ (ring);

For the binary mixture, it shows the following differences:

- the broadening of the band at $3426 \mathrm{~cm}^{-1}$ (VALS) and the increase $(\approx 60 \%)$ in intensity;

- the medium band at $1732 \mathrm{~cm}^{-1}$ from VALS's spectrum disappears;

- the most intense band $\left(1661 \mathrm{~cm}^{-1}\right)$ from the PK30's spectrum on movements at $1655 \mathrm{~cm}^{-1}$;

- the most intense band $\left(1603 \mathrm{~cm}^{-1}\right)$ from the VALS's spectrum disappears;

- the bands at 1470 and $1410 \mathrm{~cm}^{-1}$ from VALS's spectrum, respectively at 1495; 1464 and $1423 \mathrm{~cm}^{-1}$ from PK30's spectrum appear as a strip at $1464 \mathrm{~cm}^{-1}$ accompanied by a doublet on the right, at $1443 \mathrm{~cm}^{-1}$ and $1423 \mathrm{~cm}^{-1}$

- the bands from the range: $1273-816 \mathrm{~cm}^{-1}$ (VALS) and $1229-844 \mathrm{~cm}^{-1}$ (PK30) are reduced in number and they are in the form of a wide band with multiple maximus;

- also the bands from $758-515 \mathrm{~cm}^{-1}$ range (VALS) and $737-575 \mathrm{~cm}^{-1}$ (PK30) do not return to baseline in the case of the mixture, forming a band almost as wide at the top as the base. 
The FT-IR spectrum for the physical mixture between VALS and PK30 suggests some chemical interactions.

The spectrum of lactose monohydrate (a-lactose) shows a sharp medium band at $3528 \mathrm{~cm}^{-1}$ due to the vibration of $\mathrm{O}-\mathrm{H}$ band of crystallisation water. The main bands appear at:

$-3380 \mathrm{~cm}^{-1}$, as strong and large band $\left(3500-3000 \mathrm{~cm}^{-1}\right)$ stretching vibration: intermolecular hydrogen bonded;

- a doublet at 2934 and $2901 \mathrm{~cm}^{-1}$ that corresponds to the $\mathrm{C}-\mathrm{H}\left(\mathrm{CH}_{2}\right)$ stretching vibrations;

- the range of 1435 - $1341 \mathrm{~cm}^{-1}$ corresponding to the 0$H$ bending vibrations (in-plane);

- the range of $1261-1036 \mathrm{~cm}^{-1}$ which characterises the stretching vibrations $\mathrm{C}-\mathrm{O}$ (in fact $\mathrm{C}-\mathrm{O}-\mathrm{C}$ and the in plane $\mathrm{C}$ $\mathrm{H}$ bending vibrations);

- 899; 876 and $779 \mathrm{~cm}^{-1}$ that correspond to the out-ofplane $\mathrm{C}-\mathrm{H}$ bending vibration;

- 633; 604 and $552 \mathrm{~cm}^{-1}$ which correspond to the $\mathrm{O}-\mathrm{H}$ bending vibration (out-of-plane).

For the binary mixture with a-lactose, there were showed the following differences:

- the disappearance of the bands 3426; 2965; 2874; 2745 and $2616 \mathrm{~cm}^{-1}$, for the VALS spectrum;

- the bands at $3426 \mathrm{~cm}^{-1}$ (VALS), respectively $3381 \mathrm{~cm}$ -

${ }^{1}$ (a-lactose) are greatly enlarged, corresponding to the 3650

- $2500 \mathrm{~cm}^{-1}$ range;

- the significant decrease $(\approx 40 \%)$ of the bands at 1732 , respectively $1603 \mathrm{~cm}^{-1}$ from the VALS spectrum;

- the bands from $1470-515 \mathrm{~cm}^{-1}$ corresponding to VALS, respectively those from $1435-434 \mathrm{~cm}^{-1}$ corresponding to a-lactose, are grouped into three areas: $1425-1034 \mathrm{~cm}^{-1}$; $1034-760 \mathrm{~cm}^{-1}$ and $760-438 \mathrm{~cm}^{-1}$, from which the last two in particular are in the form of two wide bands with a low number for so-called maximum and a lot of shoulders. For most of the maximums, the intensity is not significantly reduced.

Based on the submitted aspects one can sustain chemical interactions between VALS and $\alpha$-lactose.

Magnesium stearate presents a weak an large band in the region $3600-3100 \mathrm{~cm}^{-1}$ (the maximum at $3264 \mathrm{~cm}^{-1}$ ). At 2918 and $2851 \mathrm{~cm}^{-1}$, there were observed two sharp

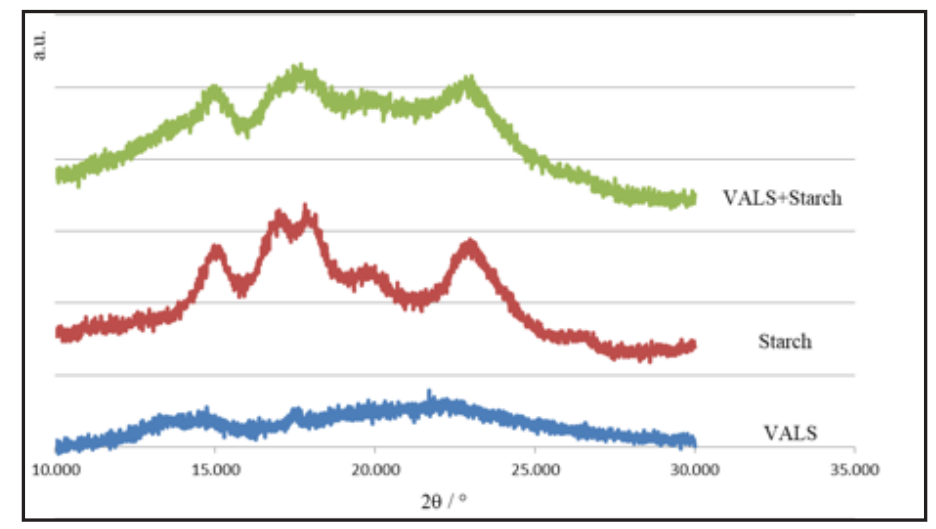

Fig. 13. X-ray diffreactogram of starch, VALS and 1:1 blend as simple mixture of VALS and starch

Fig. 14. X-ray diffreactogram of PK30, VALS and 1:1 blend as

Fig. 14. X-ray diffreactogram of PK30, VALS and
simple mixture of VALS and PK30 bands with maximum absorbtion due the $\mathrm{C}-\mathrm{H}$ vibrations from $\mathrm{CH}_{2}-\mathrm{CH}_{3}$ group. In the $1576-1472 \mathrm{~cm}^{-1}$ region, are showed asymmetric, respectively symmetric stretching vibrations corresponding to the carboxyl anion.

Other bands that must be maintained have their peaks at $2957 \mathrm{~cm}^{-1}$ corresponding to the asymmetrical vibration of $\mathrm{C}-\mathrm{H}$ band in methyl group, respectively those at $721 \mathrm{~cm}$.

${ }^{1}$ which correspond to rocking deformation $(\mathrm{H}-\mathrm{C}-\mathrm{H}) ; \mathrm{n}>3$.

The FT-IR spectrum of VALS-StMg mixture shows the following changes:

- the disappearance of the band from the region 3600 $3100 \mathrm{~cm}^{-1}$;

- the four bands from the VALS spectrum (at: 2965; 2874; 2745 and $2615 \mathrm{~cm}^{-1}$ ), respectively the two bands from the StMg spectrum (at 2918 and $2851 \mathrm{~cm}^{-1}$ ) are reducet at a doublet at 2918 and $2851 \mathrm{~cm}^{-1}$ and the intensity decrease with $\approx 50-80 \%$; $\mathrm{cm}^{-1}$;

- the significant decrease (v60\%) of the band from 1732

- the disappearance of the most intense band (1603 $\left.\mathrm{cm}^{-1}\right)$ from VALS spectrum;

- the significant decrease $(\approx 60 \%)$ of the intensity for the bands from the region 1576; 1539 and $1472 \mathrm{~cm}^{-1}$ in the StMg spectrum; intense bands from the region $810-670 \mathrm{~cm}^{-1}$ ( 758 and 723 $\left.\mathrm{cm}^{-1}\right)$.

On the bases of mentioned differences it may be considered that the VALS interacts with StMg and the appearance of the obtained products from the chemical interaction (the magnesium salt of VALS and free stearic acid).

To investigate the possible interaction of VALS with the four excipients mentioned, besides the FT-IR spectroscopy which is a qualitative analysis technique, the X-ray powder diffraction (XRPD) has been used for qualitative and quantitative identification of crystallinity. The number of the speciality articles which uses the X-ray powder diffraction is growing.

The XRPD of VALS, starch, PK30, a-lactose, StMg and of the binary mixtures are shown in figures 13-16.
- the decrease $(\approx 50 \%)$ of the intensity for the most

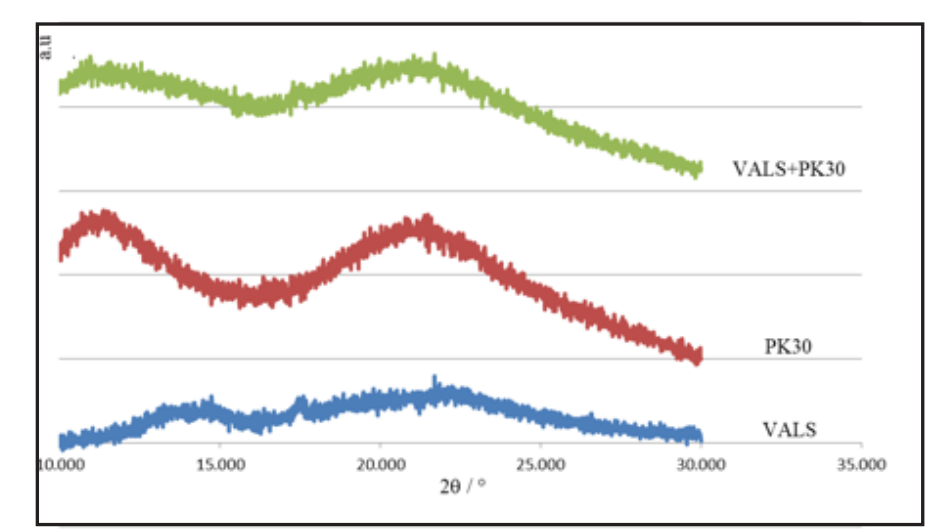



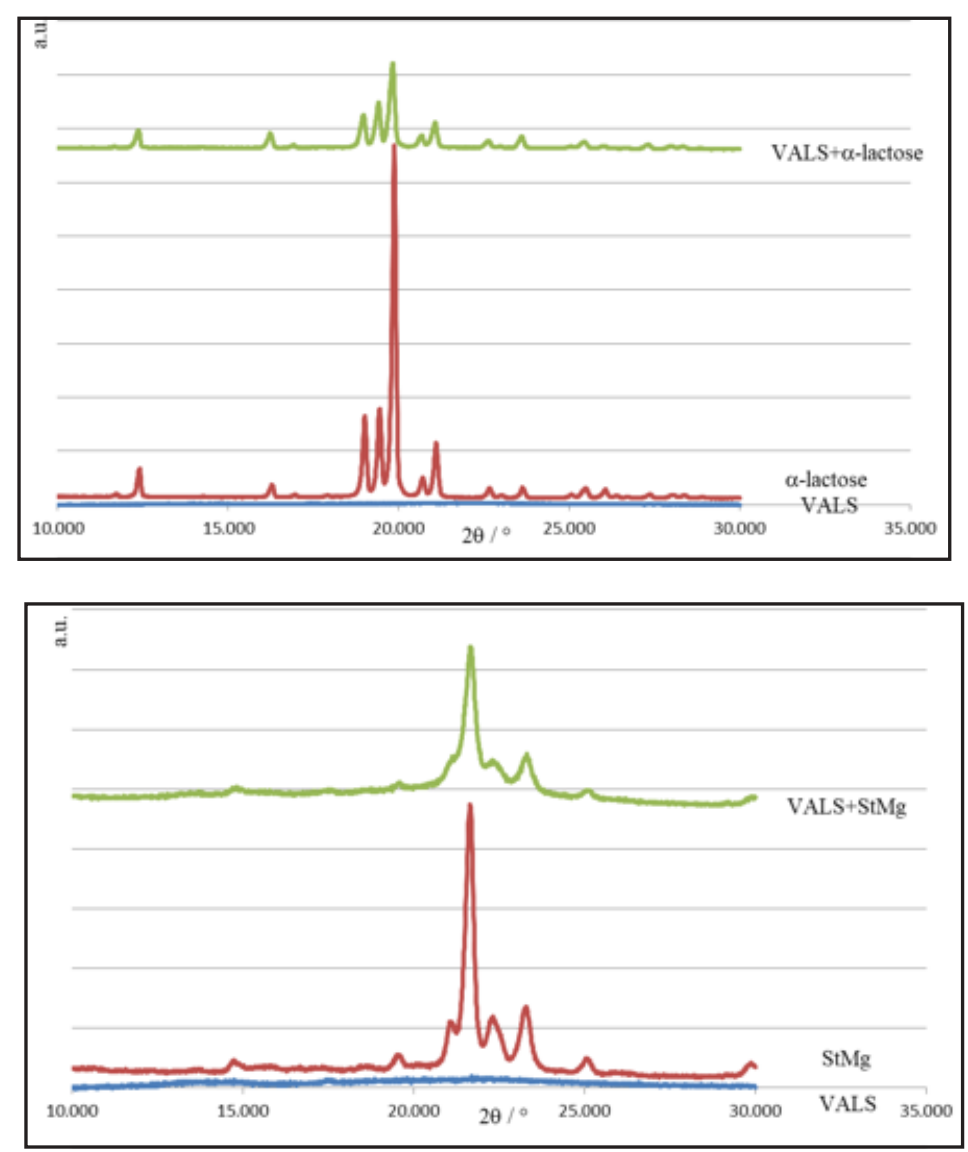

\begin{tabular}{|c|c|}
\hline \multicolumn{2}{|c|}{ VALS } \\
\hline $2 \theta$ & $\mathrm{I} \%$ \\
\hline & \\
\hline 14.740 & 70.45177 \\
\hline & \\
\hline 17.450 & 67.60584 \\
\hline 18.840 & 73.92024 \\
\hline 19.780 & 81.36696 \\
\hline 20.310 & 80.45783 \\
\hline 21.690 & 100 \\
\hline & \\
\hline 26.580 & 43.11695 \\
\hline
\end{tabular}

\begin{tabular}{|c|c|}
\hline \multicolumn{2}{|c|}{ VALS + Starch } \\
\hline $2 \theta$ & $\mathrm{I} \%$ \\
\hline & \\
\hline 14.82 & 90.71038 \\
\hline & \\
\hline 17.45 & 100 \\
\hline & \\
\hline & \\
\hline & \\
\hline 22.83 & 95.68913 \\
\hline & \\
\hline
\end{tabular}

\begin{tabular}{|c|c|}
\hline \multicolumn{2}{|c|}{ VALS } \\
\hline $2 \theta$ & $\mathrm{I} \%$ \\
\hline & \\
\hline & \\
\hline 14.740 & 70.45177 \\
\hline 17.450 & 67.60584 \\
\hline 18.840 & 73.92024 \\
\hline 19.780 & 81.36696 \\
\hline 20.310 & 80.45783 \\
\hline 21.690 & 100 \\
\hline 26.580 & 43.11695 \\
\hline
\end{tabular}

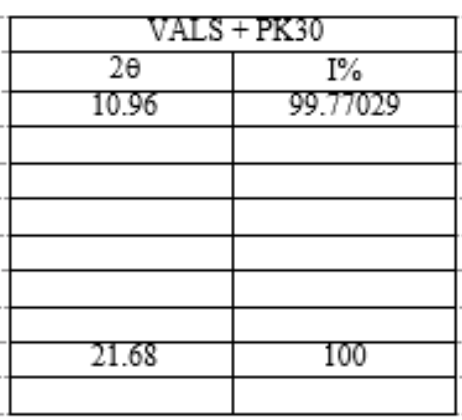

\begin{tabular}{|c|c|}
\hline \multicolumn{2}{|c|}{ VALS } \\
\hline $2 \theta$ & $\mathrm{I} \%$ \\
\hline & \\
\hline 14.740 & 70.45177 \\
\hline & \\
\hline 17.450 & 67.60584 \\
\hline 18.840 & 73.92024 \\
\hline & \\
\hline 20.780 & 81.36696 \\
\hline & 80.45783 \\
\hline 21.690 & \\
\hline & 100 \\
\hline 26.580 & 43.11695 \\
\hline
\end{tabular}

\begin{tabular}{|c|c|}
\hline \multicolumn{2}{|c|}{ VALS $+\alpha$-lactose } \\
\hline $2 \theta$ & $\mathrm{I} \%$ \\
\hline 12.34 & 22.49432 \\
\hline & \\
\hline 16.21 & 19.08795 \\
\hline & \\
\hline 18.95 & 41.0483 \\
\hline 19.4 & 54.35463 \\
\hline 19.82 & 100 \\
\hline 20.63 & 16.22169 \\
\hline 21.07 & 32.25925 \\
\hline & \\
\hline 23.57 & 14.94507 \\
\hline & \\
\hline
\end{tabular}

Fig. 15. X-ray diffreactogram of lactose, VALS and 1:1 blend as simple mixture of VALS and lactose

Fig. 16. X-ray diffreactogram of StMg, VALS and 1:1 blend as simple mixture of VALS and StMg

\begin{tabular}{|c|c|}
\hline \multicolumn{2}{|c|}{ Starch } \\
\hline $2 \theta$ & $\mathrm{I} \%$ \\
\hline 11.92 & 53.64121 \\
\hline & \\
\hline 16.93 & 96.80284 \\
\hline 17.81 & 100 \\
\hline & \\
\hline & \\
\hline & \\
\hline & \\
\hline & \\
\hline & \\
\hline
\end{tabular}

Table 2

X-RAY DIFFRACTION DATA FOR VALS, STARCH AND VALSSTARCH (1:1) MIXTURE

\begin{tabular}{|c|c|}
\hline \multicolumn{2}{|c|}{ PK30 } \\
\hline $2 \theta$ & $\mathrm{I} \%$ \\
\hline & \\
\hline & \\
\hline & \\
\hline & \\
\hline & \\
\hline & \\
\hline & 98.27791 \\
\hline 21.38 & \\
\hline & \\
\hline
\end{tabular}

Table 3

X-RAY DIFFRACTION DATA FOR VALS, PK30 ANDVALS-PK30 (1:1)

MIXTURE

\begin{tabular}{|c|c|}
\hline \multicolumn{2}{|c|}{$\alpha$-lactose } \\
\hline $2 \theta$ & $\mathrm{I} \%$ \\
\hline & \\
\hline & \\
\hline & \\
\hline 19.01 & 23.44745 \\
\hline 19.44 & 25.55492 \\
\hline 19.87 & 100 \\
\hline & \\
\hline 21.1 & 15.96519 \\
\hline & \\
\hline & \\
\hline & \\
\hline
\end{tabular}

\section{Table 4}

X-RAY DIFFRACTION DATA FOR VALS, LACTOSE AND VALSLACTOSE (1:1) MIXTURE 


\begin{tabular}{|c|c|}
\hline \multicolumn{2}{|c|}{ VALS } \\
\hline $2 \theta$ & $\mathrm{I} \%$ \\
\hline 14.740 & 70.45177 \\
\hline 17.450 & 67.60584 \\
\hline 18.840 & 73.92024 \\
\hline 19.780 & 81.36696 \\
\hline 20.310 & 80.45783 \\
\hline 21.690 & 100 \\
\hline & \\
\hline & \\
\hline 26.580 & 43.11695 \\
\hline
\end{tabular}

\begin{tabular}{|c|c|}
\hline \multicolumn{2}{|c|}{ VALS + StMg } \\
\hline $2 \theta$ & $\mathrm{I} \%$ \\
\hline & \\
\hline & \\
\hline & \\
\hline & 100 \\
\hline 21.65 & \\
\hline & 37.26137 \\
\hline 23.32 & \\
\hline & \\
\hline
\end{tabular}

The additional prominent DSC peaks in the mixtures of the drugs and excipients are a positive indication of chemical interaction of the drugs with excipients. Such interaction should result in the partial or complete disappearance of the reactant phases and appearance of new phases, which can be inferred from XRPD. X-ray diffraction patterns of the mixture, prepared at room temperature, when compared with those of its individual components showed appearance of new lines and disappearance of some of the lines present in the individual components.

The X-ray patterns of VALS-starch, respectively VALSStMg mixtures prepared at room temperature did not show the lines in addition to those present in patterns of the individual components (tables 2 and 5). However, the number of lines present in the XRD patterns of the individual components was found missing in the similar pattern recorded for the mixture. The significant difference in the $X$-ray patterns of the drug-excipient mixtures compared to those of individual drugs and excipientindicates possible incompatibility of the drugs with the excipient, even at room temperature. The presence of majority of the lines of the parent substances in the thoroughly ground mixture prepared at room temperature, however, suggests the interaction of the drug with the excipient at room temperature, which could increase with the increased temperature.

The number of new lines appeared in VALS-PK30, respectively VALS-lactose monohydrate mixtures are shown in tables 3 and 4 . The same tables indicate disappearance of some of the diffraction lines of higher, moderate and lower intensities in the mixture which are originally present in the X-ray diffraction patterns of the individual components which indicates the interaction of VALS with PK30 and lactose monohydrate.

\section{Conclusions}

In this article, a major problem has been addressed, commonly found in specialized literature, such as the compatibility and stability of drug substances with various excipients. Thus, the stability and compatibility of VALS with a number of excipients mentioned in the article was studied. As studio methods were used: thermal analysis methods, FT-IR spectroscopy and X-ray diffraction patterns (XRPD).

The results confirmed that thermal analysis is an effective and reliable technique in the compatibility studies of drug-excipient mixtures. Moreover, the DSC technique offers significant advantages, so that it is considered as a fast screening tool for drug-excipient interaction in a preformulation process.

The changes in the profile of thermoanalytical curves (TG/DTG/DSC) in the case of some binary mixtures indicate the production of some interactions as a function of heating.

According to the thermal curves, especially DSC curves, one can say that all tested excipients present lower or

\begin{tabular}{|c|c|}
\hline \multicolumn{2}{|c|}{ StMg } \\
\hline $2 \theta$ & $\mathrm{I} \%$ \\
\hline & \\
\hline & \\
\hline & \\
\hline & 100 \\
\hline 21.64 & 24.68875 \\
\hline 22.3 & 28.52923 \\
\hline 23.27 & \\
\hline & \\
\hline
\end{tabular}

Table 5

X-RAY DIFFRACTION DATA FOR VALS, StMg and VALS-StMg (1:1) MIXTURE higher interactions with VALS. This fact is supported by the differences between the values of $T_{\text {fusion }}$ and of the enthalpies of melting.

Considering that the enthalpies of melting are quantitative data since they may be expressed as a fractional change, it could be said that starch, PK30, $\alpha$ lactose and StMg certainly interact chemical with VALS. In the same context, the CCS interaction occurs in a certain etent, whilst other excipients interaction is unlikely.

The interaction of starch, PK30, $\alpha$-lactose and StMg with VALS was confirmed by FT-IR spectroscopy and by XRPD. In terms of CCS interaction with VALS, this was not confirmed by the two techniques mentioned, probably because of limited modifications.

This study shows the incompatibility of VALS with starch, PK30, $\alpha$-lactose and StMg.

\section{References}

1. VIERECK J, KUMARSWAMY R, FOINQUINOS A, XIAO K, AVRAMOPOULOS P, KUNZ M, DITTRICH M, MAETZIG T, ZIMMER K, REMKE J, Sci Transl Med 8, 2016, p. 326

2. THAO TRUONG-DINH TRAN, PHUONG HA-LIEN TRAN, JUN-BOM PARK, AND BEOM-J IN LEE, Arch Pharm Res 35, 2012, p. 1223

3. CHAPLIN S, Prescriber, 27, 2016, p. 56

4. HOWELL B.A., RAY J.A., J. Therm. Anal. Cal., 83, 2006, p. 63

5. HOWELL B.A., J. Therm. Anal. Cal., 85, 2006, p. 165

6. GAO M-J, DING X-L, HU Q-CH., Thermochim Acta., 525, 2011, p. 1.

7. DRAGOMIROIU G.T.A.B., GINGHINA O., MIRON D.S., BARCA M., POPA D.E., HIRJ AU M., LUPULEASA D., RADULESCU F.S., Farmacia, 63(2), 2015, p. 280.

8. SOOD J., SAPRA B., TIWARY A.K., AAPS PharmSciTech, 18(6), 2017, p. 1901.

9. HANGAN A.C., TURZA A., STAN R.L., STEFAN R., OPREAN L.S., Russian J ournal of Coordination Chemistry, 41(6), 2015, p. 365.

10. KLIMOVA K, LEITNER J, Thermochim Acta., 550, 2012, p. 59.

11. FULIAS A., TITA B., BANDUR G., TITA D., Rev. Chim. (Bucharest),

60, no.10, 2009, p. 1079.

12. FITA C.A., LUPULIASA D., HIRJAU V., SALA G., KARAMPELAS O., SARAMET G., Farmacia, 60(6), 2012, p.905.

13. DEDIU V., MUSAT V., JURCA B., CRISTEA N.I., Rev. Chim. (Bucharest), 68, no.8, 2017, p. 1703.

14. IORDACHE S, TUTUNARU B, SAMIDE A, POPESCU A, Rev. Chim. (Bucharest), 70, no.2, 2019, p. 503.

15. BANCUTA O. R., CHILIAN A., BANCUTA I., SETNESCU R., SETNESCU

T., ION R.M., Rev. Chim. (Bucharest), 69, no.6, 2018, p. 1346.

16. MOISEI A., GLIGOR F., BOJITA M., CHIS A., TOTAN M., VONICA-

GLIGOR L.A., CIURBA A., Farmacia, 62(6), 2014, p. 1239.

17. NITA A., TIT D.M., COPOLOVICI L., MELINTE C.E., CARMEN E., COPOLOVICI D.M., BUNGÃU S., IOVAN C., Rev. Chim. (Bucharest), 69, no. 2, 2018, p.297.

18. TITA B., MARIAN E., FULIAS A., JURCA T., TITA D., J Therm Anal Calorim. 112, 2013, p. 367.

19. TITA B., STEFANESCU M., TITA D., Rev. Chim. (Bucharest), 62, no.10, 2011, p. 1002.

20. TITA B., FULIAS A., STEFANESCU M., MARIAN E., TITA D., Rev. Chim. (Bucharest), 62, no.2, 2011, p.216.

21. TITA D., JURCA T., TITA B., J Therm Anal Calorim. 111, 2013, p. 291.

Manuscript received:15.10.2018 